\title{
The Significance of Carbon 14 in Graphite Reactor Components at End of Generation
}

\author{
Martin Metcalfe ${ }^{1 *}$, Athanasia Tzelepi ${ }^{2}$ \\ ${ }^{1}$ National Nuclear Laboratory, Stonehouse Park, Stonehouse, GL10 5UT, UK \\ ${ }^{2}$ National Nuclear Laboratory, Central Laboratory, Seascale, CA20 1PG, UK \\ Email: *ponce@cmarl.unam.mx
}

How to cite this paper: Metcalfe, M. and Tzelepi, A. (2019) The Significance of Carbon 14 in Graphite Reactor Components at End of Generation. Journal of Environmental Protection, 10, 118-129. https://doi.org/10.4236/jep.2019.102008

Received: November 22, 2018

Accepted: January 21, 2019

Published: January 24, 2019

Copyright $\odot 2019$ by author(s) and Scientific Research Publishing Inc. This work is licensed under the Creative Commons Attribution International License (CC BY 4.0).

http://creativecommons.org/licenses/by/4.0/

(c) (i) Open Access

\begin{abstract}
It is estimated that there are at least 250,000 tonnes of irradiated graphite worldwide that will require eventual disposal. This graphite arises from a number of sources, but principally comprises moderator and structural materials for experimental reactors, production reactors, commercial power reactors and fuel assemblies. In the UK, a significant proportion of its irradiated graphite is classified as Intermediate Level Waste. Such waste is not heat generating but has a radioactive content exceeding $4 \mathrm{GBq}$ per tonne alpha or 12 GBq per tonne beta/gamma activity. While the classification of waste is not consistent across states and proposals by individual states for the management of their graphite waste vary considerably, a common interest is the nature and distribution of its radioactive content. The radionuclides in irradiated graphite presenting the most significant long-term hazard are Carbon 14 (C-14) and Chlorine 36 (Cl-36) with half-lives of 5730 and 301,000 years respectively. For a better understanding of the way in which $\mathrm{C}-14$ is produced, its distribution within irradiated graphite and realistic quantification of activity can potentially lead to improved characterization to validate its status within current or future waste classifications, segregation to reduce Intermediate Level Waste volumes, or treatment to reduce activity enabling re-classification as Low Level Waste. This paper reviews all these issues and then focuses on the significance of C-14. Some findings from a National Nuclear Laboratory study of C-14 levels in carbonaceous deposits and the underlying Magnox reactor graphite are presented to illustrate the need for thorough characterization of the waste material. These results are discussed in the context of aqueous leaching of C-14 from irradiated graphite and potential treatment options to minimize aqueous release. The paper concludes with some broader observations on the significance of C-14 in nuclear reactor graphite components and how these issues should be considered when preparing the lifetime management of new nuclear plant.
\end{abstract}




\section{Keywords}

Intermediate Level Waste, Nuclear Reactor Graphite Components

\section{Introduction}

It is estimated that there are at least 250,000 tonnes of irradiated graphite worldwide (excluding China) that will require eventual disposal. This graphite arises from a number of sources, but principally comprises moderator and structural materials for experimental reactors, production reactors, commercial power reactors and fuel assemblies. States having the largest holdings of irradiated graphite are the UK, the Russian Federation, the USA and France (Figure 1) with the largest holder, the UK, estimated to have $\sim 97,000$ tonnes of irradiated graphite [1]. With the UK as an example, the bulk of its irradiated graphite is currently classified by the UK Environment Agency as intermediate level waste (ILW) (Figure 2) with a volume of $\sim 67,000 \mathrm{~m}^{3}$. As defined in the UK, such waste is not heat generating but has a radioactive content exceeding $4 \mathrm{GBq}$ per tonne alpha or $12 \mathrm{GBq}$ per tonne beta/gamma activity. ILW defined in this way must be packaged and stored in a purpose-built waste repository with all the associated significant costs. In fact, the total UK ILW inventory is estimated to contain 3,800,000 TBq of activity with approximately a quarter of this assigned to irradiated graphite [2].

While the classification of waste is not consistent across states and proposals by individual states for the management of their graphite waste vary considerably, a common interest is the nature and distribution of its radioactive content. In recent years, a number of substantial initiatives have been undertaken to investigate irradiated graphite characterization, processing, immobilization and

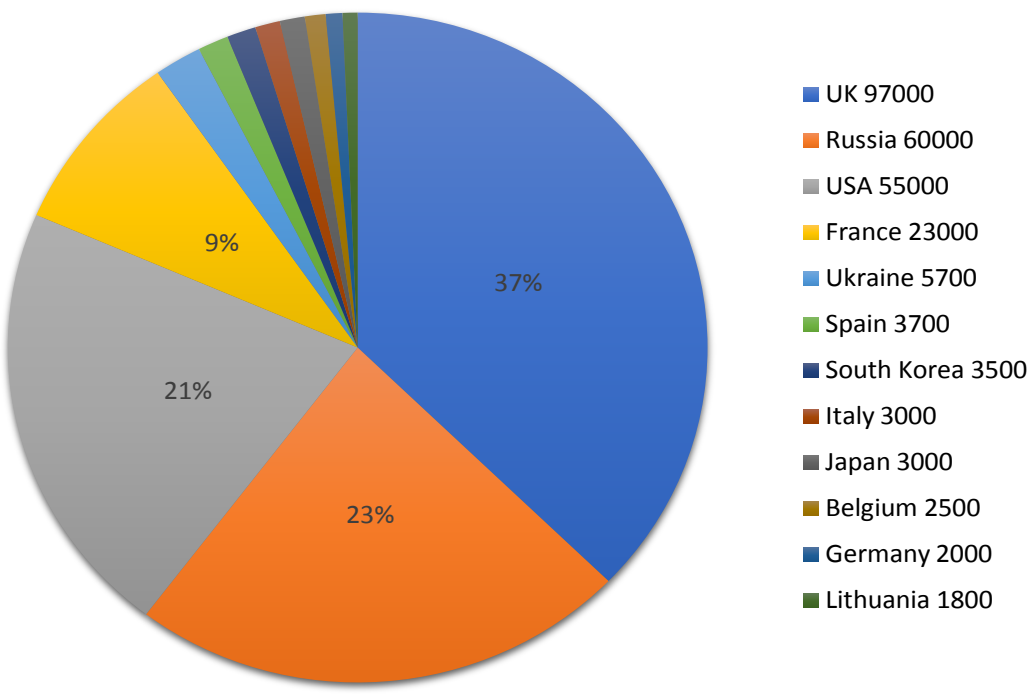

Figure 1. World inventory of irradiated graphite waste (tonnes), not including China (based on data from [1]). 
High Level (or Heat Generating) Waste (HLW) - waste in which the temperature may rise significantly as a result of their radioactivity, so this factor has to be taken into account in the design of storage or disposal facilities.

Intermediate Level Waste (ILW) - wastes exceeding the upper boundaries for LLW, but which do not require heating to be taken into account in the design of storage or disposal facilities.

Low Level Waste (LLW) - wastes having a radioactive content not exceeding $4 \mathrm{GBq}$ per tonne of alpha or $12 \mathrm{GBq}$ per tonne of beta/gamma activity.

Figure 2. UK waste classifications [2].

disposal, most notably through the EU 6th Framework Project "Carbowaste" [3], an IAEA Coordinated Research Project "Processing of Irradiated Graphite to Meet Acceptance Criteria for Waste Disposal" [1], the Euratom research project CAST (Carbon-14 Source Term) [4] and the IAEA Project GRAPA (Irradiated Graphite Processing Approaches) [5]. The radionuclides in irradiated graphite presenting the most significant long-term hazard are Carbon 14 (C-14) and Chlorine 36 (Cl-36) with half-lives of 5730 and 301,000 years respectively. Cl-36 is highly mobile, particularly in its inorganic form, but it is the behavior of C-14 that has generated most interest and study as a long-term radiological hazard.

For a better understanding of the way in which C-14 is produced, its distribution within irradiated graphite and realistic quantification of activity can potentially lead to improved characterization to validate its status within current or future waste classifications, segregation to reduce ILW volumes, or treatment to reduce activity enabling re-classification as Low Level Waste (LLW). Such understanding will also be invaluable in the context of new reactor build where strategies must be in place before construction to deal with future waste management requirements.

\section{C-14 Production and Its Significance}

While there are a number of pathways for the formation of C-14 in irradiated graphite, there are two principal pathways via neutron interactions with precursors $\mathrm{C}-13$ and $\mathrm{N}-14$. There has been considerable debate over the relative importance of these two C-14 precursors. C-13 is present in all nuclear graphite originating from fossil sources, indistinguishable from C-12 atoms, and its concentration is known to a reasonable level of accuracy (natural abundance $\sim 1.1 \%$ [6]). In contrast, $\mathrm{N}-14$ is present as an impurity from air either covalently-bonded within the graphite crystal lattice during the manufacturing process, trapped in closed porosity as air during manufacture or adsorbed on graphite surfaces during manufacture or subsequent reactor environment exposure. Consequently, the contribution from N-14 will depend upon raw materials dur- 
ing manufacture, manufacturing process and reactor operating environment. Reactors operating in air or with a cover gas of nitrogen, such as the RBMK, would see a significant contribution from $\mathrm{N}-14$ in contrast to gas-cooled (helium or carbon dioxide) reactors. A third but much less important direct thermal neutron capture pathway involves $\mathrm{O}-17$.

$$
\begin{aligned}
& \mathrm{N}-14+\mathrm{n} \rightarrow \mathrm{C}-14+\mathrm{p} \\
& \mathrm{C}-13+\mathrm{n} \longrightarrow \mathrm{C}-14+\gamma \\
& \mathrm{O}-17+\mathrm{n} \rightarrow \mathrm{C}-14+\alpha
\end{aligned}
$$

There will be some contribution to $\mathrm{C}-14$ production via $\mathrm{C}-12$ itself

$$
\begin{aligned}
& \mathrm{C}-12+\mathrm{n} \longrightarrow \mathrm{C}-13+\gamma \\
& \mathrm{C}-13+\mathrm{n} \longrightarrow \mathrm{C}-14+\gamma
\end{aligned}
$$

and a $\mathrm{C}-14$ destruction pathway by neutron capture:

$$
\begin{aligned}
& \mathrm{C}-14+\mathrm{n} \longrightarrow \mathrm{C}-15+\gamma \\
& \mathrm{C}-15 \rightarrow \mathrm{N}-15+\beta
\end{aligned}
$$

Therefore, C-14 activities in irradiated graphite will differ between reactor types and even between reactors of similar design, but all with a broadly fixed contribution from the $\mathrm{C}-13$ impurity.

The presence of $\mathrm{C}-14$ in reactor systems is regarded as a radiological hazard. In the UK, the Environment Agency sets limits on both C-14 discharges from operating plant on nuclear licensed sites as well as discharge limits at storage facilities and repositories. As shown in Figure 1, historical volumes of irradiated graphite are large and much of the graphite may be classified as ILW or equivalent, which is expensive to store long-term. Cost benefits could be significant if some or all irradiated graphite could be re-classified as LLW or equivalent. Strongly linked to waste volumes and the costs associated with packaging and storage is the behavior of C-14 within the matrix. The mobility of C-14 will influence waste management options. Depending upon its mobility, there may be potential treatment processes for removing C-14 that could subsequently lead to re-classification. Conversely, if mobility was negligible or low, this could influence the design of packaging and the type of long term storage. A better understanding of the way in which C-14 is produced, its distribution within irradiated graphite and realistic quantification of activity could potentially lead to:

- Improved characterization to validate its status within current or future waste classifications.

- Segregation based upon activity to reduce ILW volumes (or equivalent).

- Treatment to reduce activity enabling re-classification as a lower waste category.

\section{Modelling C-14 Production}

Activation modelling is a powerful tool widely used as a method for calculating radionuclide activities. The NNL approach to such modelling is similar to that adopted by other reactor physics specialists. A non-deterministic reactor physics code such as MCNPX is employed for modelling the behavior of complex reactor geometries. A processing code then converts group MCNP flux tallies to 
FISPIN (FISsion Product Inventory) libraries and finally FISPIN itself determines the irradiated nuclide inventory as a function of initial impurity concentration, reactor power, initial enrichment, irradiation and cooling time [7].

Despite the uncertainty in the $\mathrm{C}-14$ source term discussed above, activation modelling in combination with actual measurements of C-14 activities allows predictive models to be calibrated and for C-14 distributions within core components and across whole reactor cores to be quantified. Of course, any application of a localized calibration against measurement globally across a system would require justification. Predictions will only be as good as the model inputs, in particular, impurity concentrations, capture cross sections and irradiation history. If the modelling is for a complete reactor system (graphite core and coolant gas), the modelling of $\mathrm{C}-14$ production in reactor gas coolants is relatively successful since their chemical composition is known. The contribution to C-14 production in graphite from C-13 (and C-12) can be calculated with some confidence using a dynamic activation model that includes all relevant production and destruction pathways. But significant problems can arise due to large uncertainties in the contribution from $\mathrm{N}-14$. To illustrate this point, model calibrations against measurement indicate variations in nitrogen concentration at UK Magnox reactors in the range $0-10$ wppm [7], French UNGG reactors $\sim 4$ wppm [8] and the Lithuanian RBMK reactors $\sim 70$ wppm [9]. Chemical analysis for the Japanese Magnox reactor indicates concentrations in the range $40-160$ wppm [10]. An activation modelling study of the relative contributions to C-14 production from C-13 and N-14 precursors [11] has shown that an equal contribution is predicted when the nitrogen concentration reaches $\sim 10 \mathrm{wppm}$. Activation modelling studies have also shown relative distributions of C-14 across an entire Magnox reactor graphite core [7] and axially within an RBMK reactor core [9].

Activation modelling has also been used successfully to account for C-14 gaseous discharges from a UK Magnox power station [12]. Activation modelling was used to predict $\mathrm{C}-14$ production rates in both the graphite core and the carbon dioxide coolant over a selected period of operation and the results compared with monitored site C-14 discharges. Separate activation models were set up to account for principal activation routes in the graphite core and the carbon dioxide coolant gas. The $\mathrm{C}-14$ gaseous release mechanism from the graphite core was by radiolytic graphite oxidation. From a study of model predictions and measurement, it was concluded that an average nitrogen impurity level across the core was $10 \mathrm{wppm}$ and the average C-14 activity $9.55 \times 10^{4} \mathrm{~Bq} \cdot \mathrm{g}^{-1}$. It was shown that the contribution to $\mathrm{C}-14$ levels from the coolant gas was small $(\sim 15 \%)$ and that the total C-14 activity predicted to be released over a 2 year period agreed to within $5 \%$ of the figure reported to the environment agency.

This brief account of activation modelling and its application to irradiated graphite illustrates that it can be a valuable tool if used with care. Particular attention needs to be paid to impurity (C-14 precursor) concentrations and their distribution within components and across a whole core. It is also important to 
highlight the studies of Poncet and Petit [8] which caution comparison of model prediction and measurement for calibration purposes. They have observed wide discrepancies between derived impurity levels from such comparisons which they attribute to sampling phenomena relating to high purity materials.

\section{NNL Experimental Studies}

Over a number of years, NNL has been and continues to undertake an internally-funded research project entitled "Understanding the formation and behavior of C-14 in reactor graphite to support waste management". One focus of this project has been to investigate the role, if any, of carbonaceous deposits to the distribution and level of $\mathrm{C}-14$ activity in Magnox reactor graphite core components. Magnox reactor cores are known to contain surface carbonaceous deposits, which can vary in morphology depending upon operating environment (Figure 3). These deposits are easily removed by low temperature thermal treatment in air. Preliminary studies [13] have indicated that C-14 activities in these deposits are significantly higher than those in the underlying graphite. This finding has been independently confirmed in similar studies [14]. Furthermore, aqueous leaching studies on the same graphite show that there is a small more mobile fraction of C-14 with a relatively rapid rate of release of C-14 and a large stable fraction with a negligible rate of release (see for example [15] [16]). These two findings raise some interesting issues: could deposit removal be a potential treatment option that might permit re-classification of the waste graphite and is there a link between raised C-14 levels in deposits and leaching tests?

The experimental programme to investigate these issues comprises two parts:

- Thermal oxidation in air of graphite trepanned from the fuel channel wall of Magnox reactor moderator bricks.

- To quantify surface carbonaceous deposit concentrations;

- To measure C-14 activities in deposits and the underlying graphite;

- To characterize C-14 distribution within the graphite.

- Leaching tests on graphite with and without carbonaceous deposits.

- Investigate possible link between C-14 in deposits and mobile C-14 fraction during leaching.

Tests have been performed on $12 \mathrm{~mm}$ diameter $\times 6 \mathrm{~mm}$ length disc specimens which have one surface forming part of the fuel channel wall of the moderator brick. Each disc was cut into two pieces with each half undergoing a series of low $\left(450^{\circ} \mathrm{C}\right) /$ high $\left(600^{\circ} \mathrm{C}-650^{\circ} \mathrm{C}\right)$ or high/high temperature oxidations in air in a thermogravimetric analyzer (TGA) (Figure 4). The effluent gases were passed through a series of bubbler solutions to capture tritium (bottles 1 and 2-dilute nitric acid) and C-14 (bottles 3 and 4-Carbosorb) (Figure 5). A sub-set of the test specimens underwent pyrolysis and $\mathrm{C}-14$ analysis to enable the entire $\mathrm{C}-14$ content of the samples to be quantified.

Oxidation in the TGA allows the mass loss of the sample to be monitored with time. The slow oxidation enables the higher rate deposit oxidation to be 
Wylfa
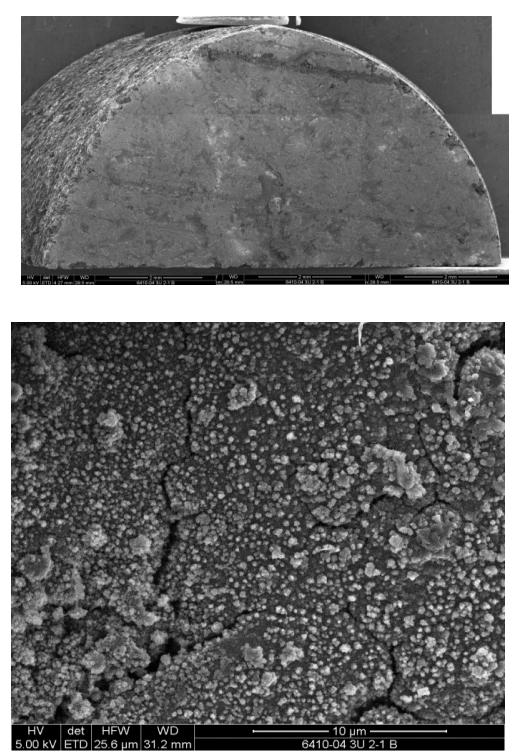

Oldbury
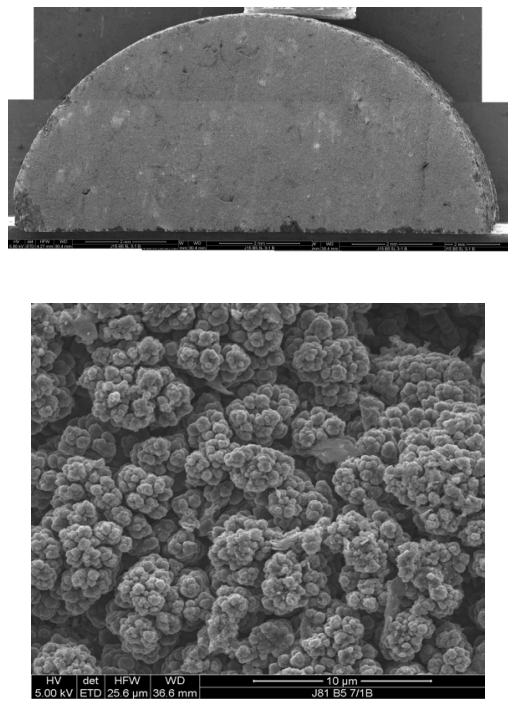

Figure 3. Contrasting surface carbonaceous deposits on graphite surfaces from two UK Magnox reactors. Upper images show $12 \mathrm{~mm}$ diameter disc, lower images show surface detail (scale $10 \mu \mathrm{m})$.

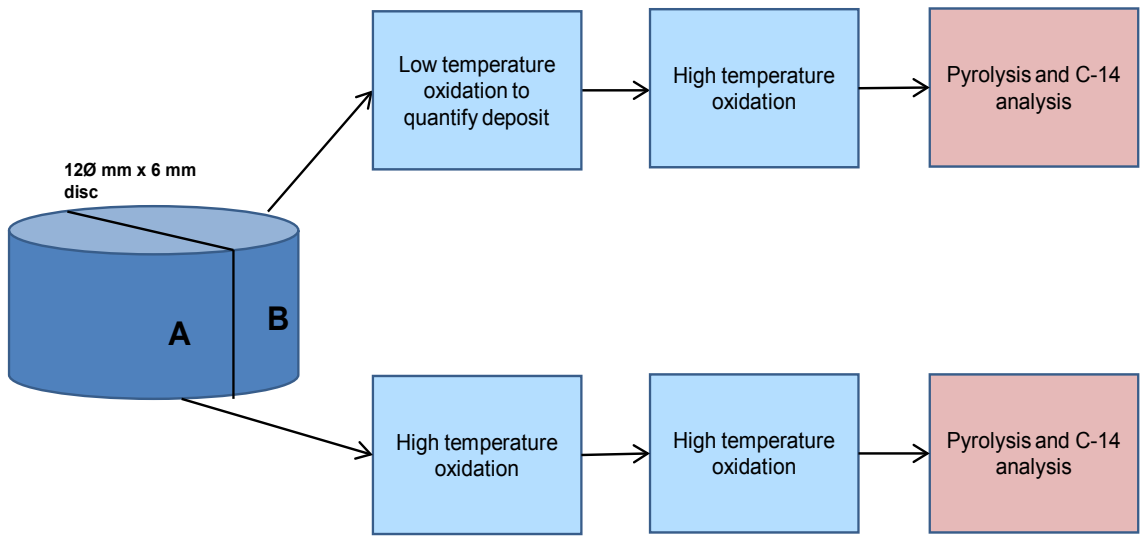

Figure 4. Schematic showing oxidation stages for the two half discs.

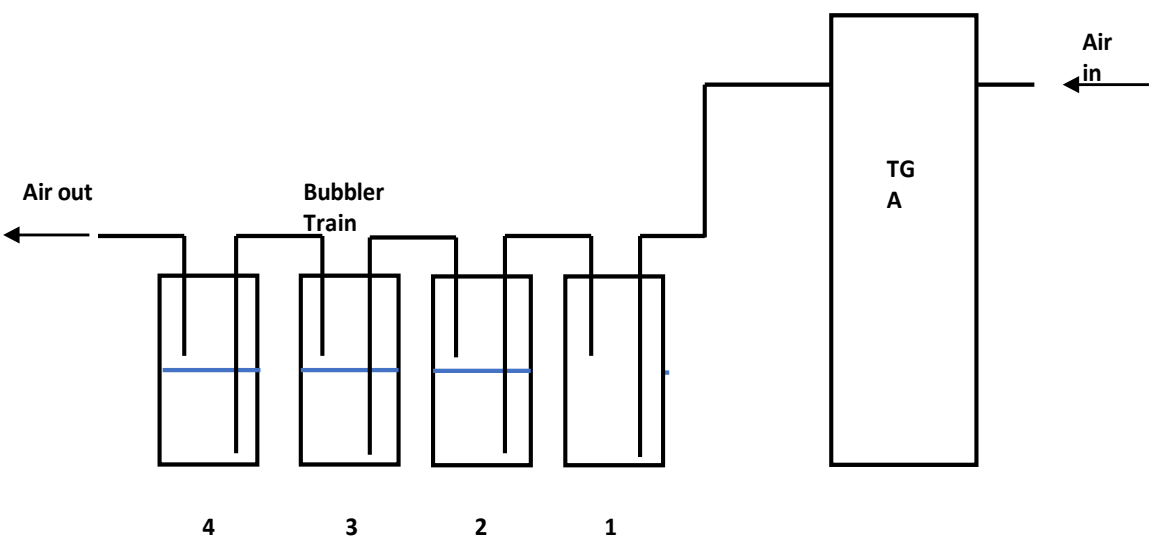

Figure 5. Schematic of experimental setup. 
monitored and by fitting the mass loss data to a two-component oxidation model, the deposit concentration to be quantified. The high temperature oxidation that follows releases $\mathrm{C}-14$ in the absence of deposit and the C-14 activity in the underlying graphite can be calculated. Knowing this activity, the total C-14 activity release from the low temperature stage can be partitioned between deposit and underlying graphite. The high/high oxidation of the other half disc provides a cross-check on C-14 activity in the underlying graphite (after correction for deposit) and also allows the C-14 activity of the underlying graphite to be measured for different mass loss steps to investigate any possible activity variation with mass loss.

C-14 activities from the preliminary studies evaluated for deposits and for the underlying graphite are summarized in Figure 6 . The figure includes data previously reported by the authors [13] together with hitherto unpublished archive data (for the underlying graphite). The $y$-axis is plotted on a log scale. C-14 activities for the deposit are approximately a factor 80 higher than those for the underlying graphite. This preliminary study has now been expanded as part of the experimental program described above to include a larger set of samples covering both the Oldbury and Wylfa Magnox reactor graphite cores. This work is approaching completion and the results are in preparation for publication.

The new leaching studies are intended to build on leaching experiments performed at NNL by the University of Manchester [16]. Irradiated graphite from an Oldbury Magnox reactor graphite core was placed in deionized water with the leachate removed for analysis and replaced at defined time intervals. In the study now being progressed, initially scoping tests have been completed on just two samples which have had their carbonaceous deposits removed by thermal oxidation in air at $450^{\circ} \mathrm{C}$ (thereby removing a negligible amount of the underlying graphite). The samples were then put through a similar leaching regime as those tested by Manchester, but in this case with leachates replaced at 1, 4 and 20 days. The findings are not reproduced here, but they clearly show similar behavior to that of the untreated graphite.

The findings so far from this ongoing study can be summarized as follows. Carbonaceous deposits present in the Oldbury Magnox reactor core have C-14 activities orders of magnitude higher than those of the underlying graphite. Based upon a very small experimental study, the initial release of C-14 during aqueous leaching does not seem to be associated with carbonaceous deposits. There is clear evidence for a small mobile fraction of C-14 under leaching conditions but a significant portion is released at extremely low rates.

It is instructive at this stage to look at C-14 activities in graphite reported for other reactors. These are summarized in Table 1. Any comparison should be treated with care as some values are based on measurements on discrete samples and others (French data) are estimates for an entire core. Magnox and UNGG values are broadly similar, as expected RBMK values for graphite under nitrogen cover are significantly higher. 


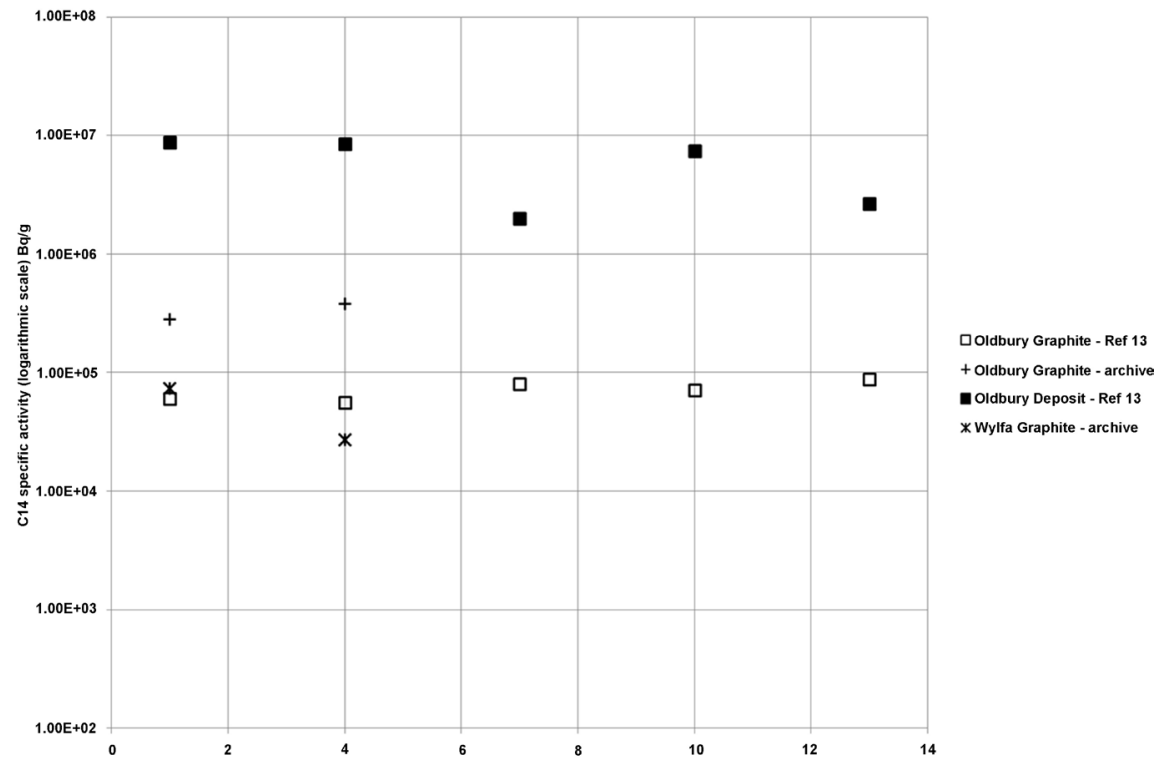

Figure 6. C-14 activities ( $\left.\mathrm{Bq} \mathrm{g}^{-1}\right)$ in carbonaceous deposits and underlying graphite.

Table 1. C-14 activities measured in graphite from other reactors.

\begin{tabular}{cc}
\hline Reactor & C-14 activity $(\mathrm{Bq} / \mathbf{g})$ \\
\hline UK Magnox (Oldbury) & $9.8 \mathrm{E} 04$ \\
UK Magnox (Wylfa) & $8.6 \mathrm{E} 04$ \\
Japan Magnox (Tokai) [10] & $\sim 8.4 \mathrm{E} 04$ \\
Lithuania RBMK (Ignalina) [17] & $\sim 5.2 \mathrm{E} 04$ to $3.6 \mathrm{E} 05$ \\
France UNGG (Bugey 1) [18] & $\sim 12.6 \mathrm{E} 04$ \\
France UNGG (Chinon A3) [18] & $\sim 4.0 \mathrm{E} 04$ \\
Spain Magnox (Vandellos) [19] & $\sim 5.6 \mathrm{E} 04$ \\
\hline
\end{tabular}

\section{Treatment before Storage?}

It is beyond the scope of this paper to discuss in any detail graphite waste management strategies. These are considered at length elsewhere, for example in IAEA and Carbowaste publications [1] [20]. Custodians of historical volumes of irradiated graphite initially have the choice of ongoing storage in existing repositories (legacy waste), "safe store" within original reactor containment with or without future disassembly/storage/disposal, early or deferred disassembly/storage/disposal. Disassembly could be by the removal of intact individual graphite components or by some destructive mechanical means. Examples of the former option are the disassembly of the Windscale Advanced Gas-cooled Reactor (WAGR) and the Graphite Low Energy Experimental Reactor (GLEEP) in the UK. An example of the latter is the disassembly of the Brookhaven experimental reactor in the US where a mechanical digger was used to break up the core for removal. There are also well-advanced proposals for mechanical disassembly using what is described as "nibble and vac", in which grinding equipment breaks up the core and the resulting ground material is extracted using a 
vacuum device. Whichever means of disassembly is employed, a decision is required on whether the graphite is sent for storage in a treated or untreated state.

The objectives of treatment could include volume reduction (through to the extreme of complete gasification), removal of mobile radionuclides by a range of physical or chemical processes to enable re-classification or more secure storage or immobilization to limit/prevent release of radionuclides. Any treatment must be preceded by detailed characterization. The NNL research on C-14 presented here investigates one particular aspect of treatment relevant to UK Magnox reactor graphite. The presence of high C-14 activities in carbonaceous deposits is non-intuitive but suggests that the precursor is almost certainly nitrogen in air that adsorbs onto surfaces or surface deposits. There is the opportunity for replenishment during reactor maintenance outages when the core is exposed to air. The ability of nitrogen to be adsorbed on graphite surfaces is well-documented [21], albeit under extreme conditions. The benefits of low temperature thermal treatment to remove these deposits provide little impact based upon current UK waste classifications. Based upon the concentration of deposit and its associated C-14 activity, the total C-14 activity of a whole moderator brick can be partitioned between brick and deposit. The NNL data for a $6 \mathrm{~mm}$ annulus of graphite at the fuel channel wall of a moderator brick indicates that approximately $5 \%$ of the total activity can be attributed to deposit (noting that C-14 produced in deposits cannot be predicted by activation modelling). This figure will be low for an entire brick as it is known that deposits are present to a lesser extent on internal surfaces away from the region under investigation. Its removal would not have any impact on the waste classification. This does not close out such an approach - the possibility of $\mathrm{C}-14$ gradients in the graphite might still point to benefits from treatment to remove material close to external and pore surfaces.

\section{Conclusions and Implications for New Build}

While the general characteristics of irradiated graphite and the behavior of C-14 have been studied extensively, any assessment of graphite waste management options for material from a specific plant or facility will require an understanding of that material in relation to its manufacture, irradiation history and chemical environment during irradiation. Such characterization of the graphite is essential in order to select the optimal waste management strategy. Characterization will be improved by a combination of sampling and activation modelling. An understanding of C-14 behavior requires experimental study as production and release mechanisms cannot be predicted with confidence.

While "safe store" is an attractive option, allowing efforts to be focused on more hazardous aspects of reactor decommissioning, an understanding of the nature of the radiological hazard associated with irradiated graphite and its impact on final storage/disposal should ideally be addressed now while the expertise exists and access to the cores is (mostly) possible.

Irradiated graphite volumes and total C-14 activity levels are high which will 
impact on final storage/disposal. The release of C-14 from irradiated graphite is low except under extreme conditions. This finding is encouraging for long term storage. It also suggests that there may not be easy treatment options to reduce activity and change assigned waste classifications.

There is a strong likelihood that graphite will continue to feature in next generation reactor designs such as high temperature gas-cooled reactors (HTR) and molten salt reactors. While it will not be possible to make accurate predictions about the state of the graphite after irradiation, the experience that has accumulated over recent years should guide designers and operators in the preparation of final decommissioning and waste management solutions.

\section{Conflicts of Interest}

The authors declare no conflicts of interest regarding the publication of this paper.

\section{References}

[1] International Atomic Energy Agency (2016) IAEA-TECDOC-1790. ISBN: 978-92-0-104016-9. Processing of Irradiated Graphite to Meet Acceptance Criteria for Waste Disposal, 2016, 148 p.

[2] Nuclear Decommissioning Authority (2016) Radioactive Waste in the UK-Radioactive Waste Inventory Report.

[3] Metcalfe, M.P., Banford, A.W., Eccles, H. and Norris, S. (2013) EU Carbowaste Project: Development of a Toolbox for Graphite Waste Management. Journal of Nuclear Materials, 436, 158-166. https://doi.org/10.1016/j.jnucmat.2012.11.016

[4] Neeft, E.A.C. (2018) CArbon-14 Source Term CAST: Summary of the Progress Achieved through CAST for the General Public and Decision Makers, D7.25. https://www.projectcast.eu/publications

[5] Wickham, A., Steinmetz, H.-J., O'Sullivan, P. and Ojovan, M.I. (2017) Updating Irradiated Graphite Disposal: Project "GRAPA" and the International Decommissioning Network. Journal of Environmental Radioactivity, 171, 34-40. https://doi.org/10.1016/j.jenvrad.2017.01.022

[6] Coplen, T.B., Böhlke, J.K., De Bièvre, P., Ding, T., Holden, N.E., Hopple, J.A., Krouse, H.R., Lamberty, A., Peiser, H.S., Revesz, K., Rieder, S.E., Rosman, K.J.R., Roth, E., Taylor, P.D.P., Vocke Jr., R.D. and Xiao, Y.K. (2002) Isotope-Abundance Variations of Selected Elements. Pure and Applied Chemistry, 74, 1987-2017. https://doi.org/10.1351/pac200274101987

[7] Mills, R.W., Riaz, Z. and Banford, A.W. (2012) Nuclear Data Issues in the Calculation of $\mathrm{C} 14$ and $\mathrm{Cl} 36$ in Irradiated Graphite. Proceedings of the European Nuclear Conference-ENC 2012, European Nuclear Society, Brussels, 2012, Report No. INIS-XE-13-0003.

[8] Poncet, B. and Petit, L. (2013) Method to Assess the Radionuclide Inventory of Irradiated Graphite Waste from Gas-cooled Reactors. Journal of Radioanalytical and Nuclear Chemistry, 298, 941-953. https://doi.org/10.1007/s10967-013-2519-6

[9] Narkunas, E., Smaizys, A., Poskas, P. and Bartkus, G. (2016) Modelling of the Spatial Distribution of the Induced Activities in the RBMK-1500 Reactor Graphite Blocks and Rings/Sleeves. Progress in Nuclear Energy, 91, 265-276. 
https://doi.org/10.1016/j.pnucene.2016.05.005

[10] Takahashi, R., Toyahara, M., Maruki, S. and Ueda, H. (1999) Nuclear Graphite Waste Management. Proceedings of a Technical Committee Meeting, Manchester, October 1999. https://inis.iaea.org

[11] Black, G. (2014) Irradiated Graphite Waste: Analysis and Modelling of Radionuclide Production with a View to Long Term Disposal. Ph.D. Thesis, University of Manchester, Manchester.

[12] Metcalfe, M.P. and Mills, R.W. (2015) Radiocarbon Mass Balance for a Magnox Nuclear Power Station. Annals of Nuclear Energy, 75, 665-671. https://doi.org/10.1016/j.anucene.2014.08.071

[13] Metcalfe, M.P., Tzelepi, A. and Gill, J. (2016) Carbon 14 Content of Carbonaceous Deposits in Oldbury Core Graphite. CD ROM Attachment to IAEA-TECDOC-1790. Processing of Irradiated Graphite to Meet Acceptance Criteria for Waste Disposal [1].

[14] Payne, L., Heard, P. and Scott, T.B. (2016) Examination of Surface Deposits on Oldbury Reactor Core Graphite to Determine the Concentration and Distribution of 14C. PLOS ONE, 11, e0164159.

[15] Bradbury, D. and Wickham, A.J. (2008) Graphite Leaching: A Review of International Aqueous Leaching Data with Particular Reference to the Decommissioning of Graphite Moderated Reactors. EPRI, B.D.T. Ltd., Palo Alto, CA.

[16] Hagos, B. (2013) Microstructural and Chemical Behaviour of Irradiated Graphite Waste under Repository Conditions. Ph.D. Thesis, University of Manchester, Manchester.

[17] Narkunas, E., Smaizys, A., Poskas, P. and Kilda, R. (2010) Assessment of Different Mechanisms of C-14 Production in Irradiated Graphite of RBMK-1500 Reactors. Kerntechnik, 75, 185-194. https://doi.org/10.3139/124.110083

[18] Poncet, B. (2013) Method to Assess the Radionuclide Inventory of Irradiated Graphite from Gas-Cooled Reactors. Annual Waste Management Symposium (WM2013); International Collaboration and Continuous Improvement, Phoenix 2013, 6939-6953.

[19] Márquez, E., Piña, G., Rodriguez, M., Fachinger, J., Grosse, K.-H., Nieto, J.L.L., Gracian, M.Q. and Seemann, R. (2011) GRAFEC: A New Spanish Program to Investigate Waste Management Options for Radioactive Graphite. Annual Waste Management Symposium ( WM2012); Improving the Future in Waste Management, Phoenix 2012, 3210-3224.

[20] Wareing, A., Abrahamsen-Mills, L., Fowler, L., Grave, M., Jarvis, R., Metcalfe, M., Norris, S. and Banford, A.W. (2017) Development of Integrated Waste Management Options for Irradiated Graphite. Nuclear Engineering and Technology, 49, 1010-1018. https://doi.org/10.1016/j.net.2017.03.001

[21] LaBrier, D. and Dunzik-Gougar, M.L. (2015) Identification and Location of ${ }^{14}$ C-Bearing Species in Thermally Treated Neutron Irradiated Graphites NBG-18 and NBG-25: Pre- and Post-Thermal Treatment. Journal of Nuclear Materials, 460, 174-183. https://doi.org/10.1016/j.jnucmat.2015.01.063 